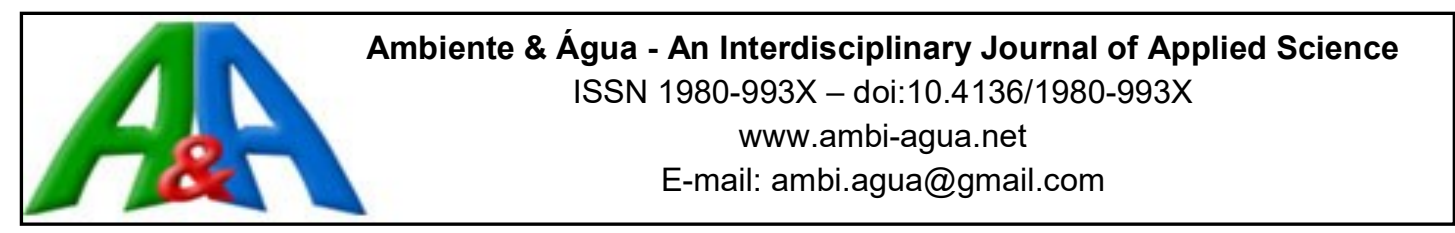

\title{
Análise hidroambiental da microbacia do Pirajibu-Mirim, Sorocaba, SP, Brasil
}

\author{
doi:10.4136/ambi-agua.1969
}

Received: 14 Jul. 2016; Accepted: 12 Sep. 2016

\author{
Carina Júlia Pensa Corrêa*; Kelly Cristina Tonello; Fernando Silveira Franco \\ Universidade Federal de São Carlos (UFSCar), Sorocaba, SP, Brasil \\ Departamento de Ciências Ambientais \\ *Autor correspondente: e-mail: carinapensa@gmail.com, \\ kellytonello@ufscar.br, fernandosf@ufscar.br
}

\section{RESUMO}

A microbacia hidrográfica do rio Pirajibu-Mirim, localizada em Sorocaba-SP, contribui para produção e o abastecimento de água do município, além de estar inserida em uma região prioritária para implantação de um programa de Pagamentos por Serviços Ambientais (PSA). Nesse contexto, o presente trabalho objetivou avaliar a conservação de suas nascentes e a adequação ambiental de suas Áreas de Preservação Permanente (APPs). Para tanto, foi realizado em campo um diagnóstico macroscópico das nascentes, para sua posterior classificação. A avaliação da adequação ambiental nas APPs foi realizada com o auxílio de imagens do satélite RapidEye (2014) e do programa Quantum GIS 1.6. Os resultados apontam que a qualidade da água destaca-se positivamente, enquanto o uso e ocupação do solo e a área das nascentes apresentam resultados negativos. Nenhuma nascente está localizada em área protegida e apenas uma está em propriedade rural agrícola, além de não possuírem placas indicativas. A maioria apresenta sinais de perturbação antrópica, como a degradação da vegetação e depósito de lixo. A avaliação da adequação ambiental mostrou que $30,7 \%$ das APPs da microbacia estão sem vegetação e, assim, deveriam sofrer intervenções visando à recuperação das áreas degradadas. A análise do perfil das propriedades que possuem nascentes indicou a predominância de terrenos ociosos e chácaras. Os dados encontrados evidenciam algumas características ambientais e socioeconômicas da microbacia que, se consideradas na implementação do programa de PSA, podem contribuir para a sustentabilidade de uma política pública de conservação dos recursos hídricos na região.

Palavras-chave: adequação ambiental, manejo de bacias hidrográficas, nascentes, pagamento por serviços ambientais.

\section{Hydrological and environmental analysis of the Pirajibu-Mirim watershed, Sorocaba, SP, Brazil}

\begin{abstract}
The watershed of the Pirajibu-Mirim River, in Sorocaba-SP, contributes to production and the municipal water supply, and is located in a high-priority region for the implementation of a Payment for Environmental Services (PES) program. In this context, this study aimed to evaluate the conservation of its water springs and environmental compliance
\end{abstract}


with the legislation of Permanent Preservation Areas (PPAs). A macroscopic diagnosis of the water springs was therefore made in the field in order to subsequently classify their condition. The assessment of environmental compliance with the PPAs was performed with the aid of RapidEye (2014) satellite images and the Quantum GIS 1.6 program. The results indicated that water quality stands out positively, while the land use and occupation of the springs areas showed negative results. No water spring is located in protected areas and only one was found on an agricultural farm; none had signs indicating its presence. Most of them show evidence of human disturbance, such as degradation of vegetation and garbage dumping. The evaluation of environmental compliance demonstrated that $30.7 \%$ of the PPAs lack adequate vegetative cover, and thus may potentially be included in an intervention program for recovery due to degradation. The profile analysis of the properties that have water springs indicated the predominance of lands without any commercial use that included recreational country houses. The work indicated some environmental and socioeconomic characteristics of the watershed that can support public policy for the conservation of water resources in the region, if considered in the establishment of a PSA program.

Keywords: environmental compliance, payment for ecosystem services, springs, watershed management.

\section{INTRODUÇÃO}

Os recursos hídricos são imprescindíveis para a manutenção da vida, tanto para o suprimento de necessidades básicas quanto para o desenvolvimento social e tecnológico dos seres humanos. Dessa forma, diversas legislações pautam a proteção e manutenção desses recursos, como o Código Florestal Brasileiro. A atual lei sobre a proteção da vegetação nativa ( $\left.{ }^{\circ} 12.651 / 2012\right)$ define áreas que são especialmente protegidas, como aquelas no entorno de corpos d'água e de nascentes ou olhos d'água perenes (Brasil, 2012).

A Política Nacional dos Recursos Hídricos (PNRH) também visa o uso sustentável dos recursos hídricos, estabelecendo seu manejo de forma integrada. A PNRH estabelece ferramentas para diminuir os impactos antrópicos na ocupação e uso do solo, adotando como unidade territorial de gerenciamento a bacia hidrográfica (Brasil, 1997).

O estabelecimento da bacia hidrográfica como unidade de planejamento beneficiou principalmente a proteção da água, já que sua delimitação está diretamente relacionada com a disposição dos recursos hídricos (Porto e Porto, 2008). Para sua gestão, concebeu-se um modelo compartilhado, onde o poder público e a comunidade têm responsabilidades e relevância para tomada de decisões (Brasil, 1997).

O Comitê de Bacias Hidrográficas Sorocaba Médio Tietê (CBH-SMT) engloba a região da sub-bacia do Pirajibu. O CBH-SMT possui câmaras técnicas responsáveis por assessorar o Conselho Estadual de Recursos Hídricos em suas decisões, e grupos de trabalho para análise de temas específicos. Um de seus grupos discute a criação e a implementação de projetos de Pagamento por Serviços Ambientais (PSA) nos municípios que integram a bacia (ANA, 2011).

A elaboração de projetos de PSA em uma bacia depende da determinação de diversos aspectos, entre eles os serviços ambientais que serão priorizados (Bohlen et al., 2009). Esses projetos podem ser desenvolvidos com diversos objetivos e estruturas. No entanto, para serem bem sucedidos, devem se adaptar às particularidades das regiões onde são adotados (Schomers e Matzdorf, 2013; Ezzine-de-Blas et al., 2016)

$\mathrm{O}$ presente trabalho objetivou analisar a conservação das nascentes e a adequação ambiental das APPs da microbacia do Pirajibu-Mirim, em Sorocaba/SP. A microbacia foi escolhida pela sua inserção na bacia do Pirajibu, adotada como prioritária para o recebimento 
de PSA na lei municipal de Sorocaba $n^{\circ}$ 162/2011 (Sorocaba, 2011), e pela sua importância no abastecimento público de água na cidade. Como a lei ainda não foi regulamentada, os dados fornecidos pelo trabalho podem auxiliar no desenvolvimento de um projeto adequado para a região.

\section{MATERIAL E MÉTODOS}

\section{1. Área de estudo}

O município de Sorocaba localiza-se no sudeste do estado de São Paulo, a $92 \mathrm{~km}$ de distância da capital, na chamada borda de depressão periférica paulista (IGC, 2014). O clima da região é tropical de altitude, marcado por períodos chuvosos no verão e secos de inverno. Segundo a classificação de Koeppen, o clima é Cwa, com mínimas de $12^{\circ} \mathrm{C}$ e máximas de $30^{\circ} \mathrm{C}$, sendo a média anual $22,1^{\circ} \mathrm{C}$. A precipitação média anual gira em torno de $1.311 \mathrm{~mm}$. (CEPAGRI, 2015).

A vegetação é caracterizada por uma área de ecótono entre Mata Atlântica e Cerrado, com a presença das fitofisionomias: floresta estacional semidecidual, floresta ombrófila densa, cerrado, campos cerrados e matas de várzea (Sorocaba, 2014). Entretanto, de acordo com Lourenço et al. (2014), atualmente apenas 4,46\% da área do município permanece coberta por fragmentos florestais em estágios médios ou avançados de regeneração.

Sorocaba cobre uma área de $449 \mathrm{~km}^{2}$, com população estimada de 644.919 habitantes, sendo 99\% residentes na zona urbana (IBGE, 2015). Seu perímetro está inserido na Unidade de Gerenciamento de Recursos Hídricos do Rio Sorocaba e Médio Tietê (UGRHI- 10), que abrange 34 municípios paulistas e compreende uma área de drenagem de aproximadamente $6830 \mathrm{~km}^{2}$. O corpo d'água que atravessa e designa a cidade é o rio Sorocaba, principal afluente da margem esquerda do rio Tietê (IGC, 2014).

A microbacia do Pirajibu-Mirim foi determinada como área prioritária para o estudo pela importância de seus recursos hídricos, seu potencial para conexão de fragmentos florestais e sua inserção completa no município de Sorocaba (Figura 1). Além de corresponder a uma área estratégica para conservação e recuperação de vegetação nativa e recursos hídricos, o Pirajibu-Mirim ainda é um rio de grande importância para o abastecimento de água na cidade. De acordo com o SAAE (2014), corresponde a 10\% da água tratada e distribuída para população, através da represa do Pirajibu.

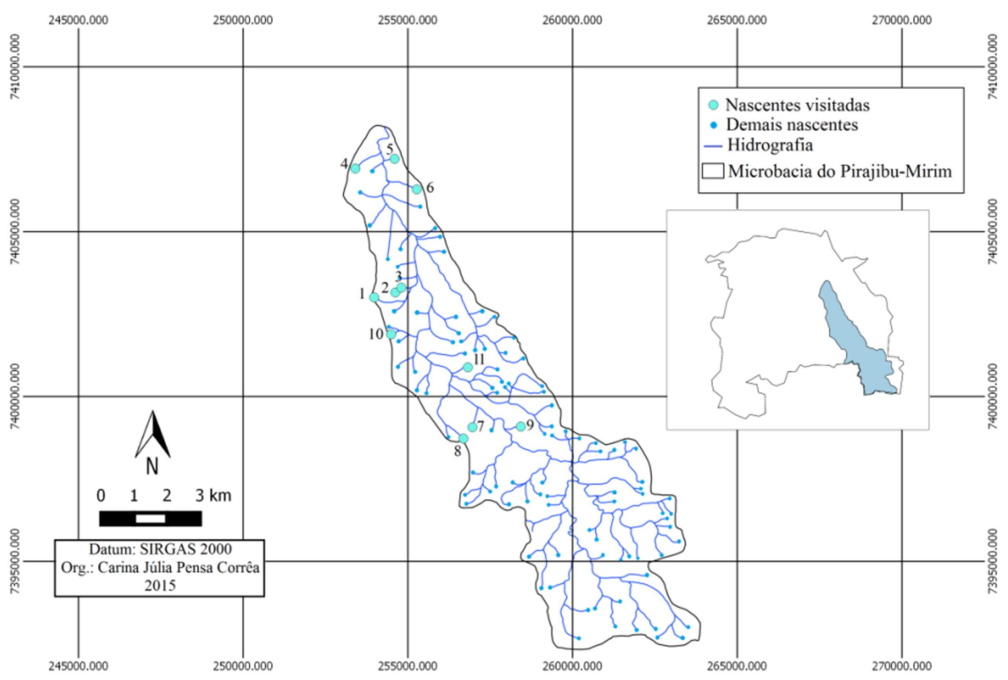

Figura 1. Delimitação da microbacia do rio Pirajibu-Mirim e sua inserção no município de Sorocaba/SP, localização das nascentes da microbacia e identificação das nascentes visitadas em campo, 2015. 


\subsection{Diagnóstico das nascentes}

As nascentes foram previamente localizadas com o auxílio de cartas do IBGE (1996), de resolução 1:50.000, e com os mapas elaborados no programa Quantum GIS 1.6, software livre de Sistemas de Informações Geográficas. Posteriormente, elas foram conferidas em campo com o auxílio de um navegador portátil configurado com DATUM WGS84, UTM, zona 23S. Nas nascentes que puderam ser acessadas, foi aplicado um diagnóstico simplificado, baseado no modelo de Gomes et al. (2006). Foi realizada uma análise macroscópica a fím de categorizar as nascentes de acordo com seu estado de conservação (Tabela 1).

Após a somatória da pontuação de cada nascente, elas foram classificadas como A-ótima (Entre 39 e 37 pontos), B- boa (Entre 36 e 34), C- razoável (Entre 33 e 31), D- ruim (Entre 30 e 28) e E-péssima (Abaixo de 28).

Tabela 1. Parâmetros para diagnóstico macroscópico qualitativo aplicado às nascentes.

\begin{tabular}{|c|c|c|c|}
\hline \multirow{2}{*}{ Parâmetros } & \multicolumn{3}{|c|}{ Pontuação } \\
\hline & 1 & 2 & 3 \\
\hline Cor da água & Escura & Clara & Transparente \\
\hline Odor & Cheiro forte & Cheiro fraco & Sem cheiro \\
\hline Lixo ao redor & Muito & Pouco & Sem lixo \\
\hline Materiais Flutuantes & Muito & Pouco & Ausência \\
\hline Óleos & Muito & Pouco & Ausência \\
\hline Espumas & Muito & Pouco & Ausência \\
\hline Esgoto & Esgoto doméstico & $\begin{array}{l}\text { Fluxo } \\
\text { Superficial }\end{array}$ & Ausência \\
\hline Vegetação (APP) & Alta degradação & $\begin{array}{l}\text { Baixa } \\
\text { degradação }\end{array}$ & Preservada \\
\hline Uso por animais & Presença & Apenas marcas & Ausência \\
\hline Uso por humanos & Presença & Apenas marcas & Não detectado \\
\hline Proteção do local & Sem proteção & $\begin{array}{l}\text { Com proteção } \\
\text { acessível }\end{array}$ & $\begin{array}{l}\text { Com proteção } \\
\text { inacessível }\end{array}$ \\
\hline $\begin{array}{l}\text { Proximidade com } \\
\text { residências/Estabelecimentos }\end{array}$ & $<50$ metros & $\begin{array}{l}\text { Entre } 50 \text { e } 100 \\
\text { metros }\end{array}$ & $>100$ metros \\
\hline Área de inserção & Ausente & Privada & Área protegida \\
\hline
\end{tabular}

Fonte: Adaptado de Gomes et al. (2006).

Para análise da adequação ambiental das nascentes e demais corpos d'agua foram utilizadas imagens de satélite RapidEye (2014), fornecidas pelo Ministério do Meio Ambiente (MMA) e processadas no programa Quantum GIS 1.6. Os perímetros correspondentes às Áreas de Preservação Permanente (APPs) foram classificados de acordo com o uso do solo (fragmentos florestais; pasto/solo descoberto; floresta plantada; instalações urbanas e lagoas).

\section{RESULTADOS E DISCUSSÃO}

\subsection{Diagnóstico das nascentes}

De acordo com as cartas do IBGE (1996), existem 109 nascentes na microbacia. No entanto, o diagnóstico foi aplicado em apenas 11 delas (Figura 2, Tabela 2). Embora toda 
microbacia tenha sido percorrida, o número de nascentes avaliadas reflete a dificuldade de acesso aos locais onde elas possivelmente se encontram.

A maioria das nascentes está localizada em terrenos particulares que, sem a devida permissão, não puderam ser visitados. Observou-se que essas propriedades são majoritariamente terrenos ociosos ou chácaras. Apenas uma nascente foi encontrada em propriedade de uso agrícola. Esse aspecto deve ser levado em consideração na elaboração do projeto de PSA, pois grande parte dos modelos encontrados no Brasil e no mundo, quando remunera pessoas físicas, considera as propriedades com uso econômico do solo (Guedes e Seehusen, 2011; Wunder, 2008). Rosa et al. (2016) destacam a possibilidade de reversão dos apoios monetários a outras formas de apoio, de acordo com o perfil socioeconômico encontrado na área prioritária para conservação do serviço ambiental.

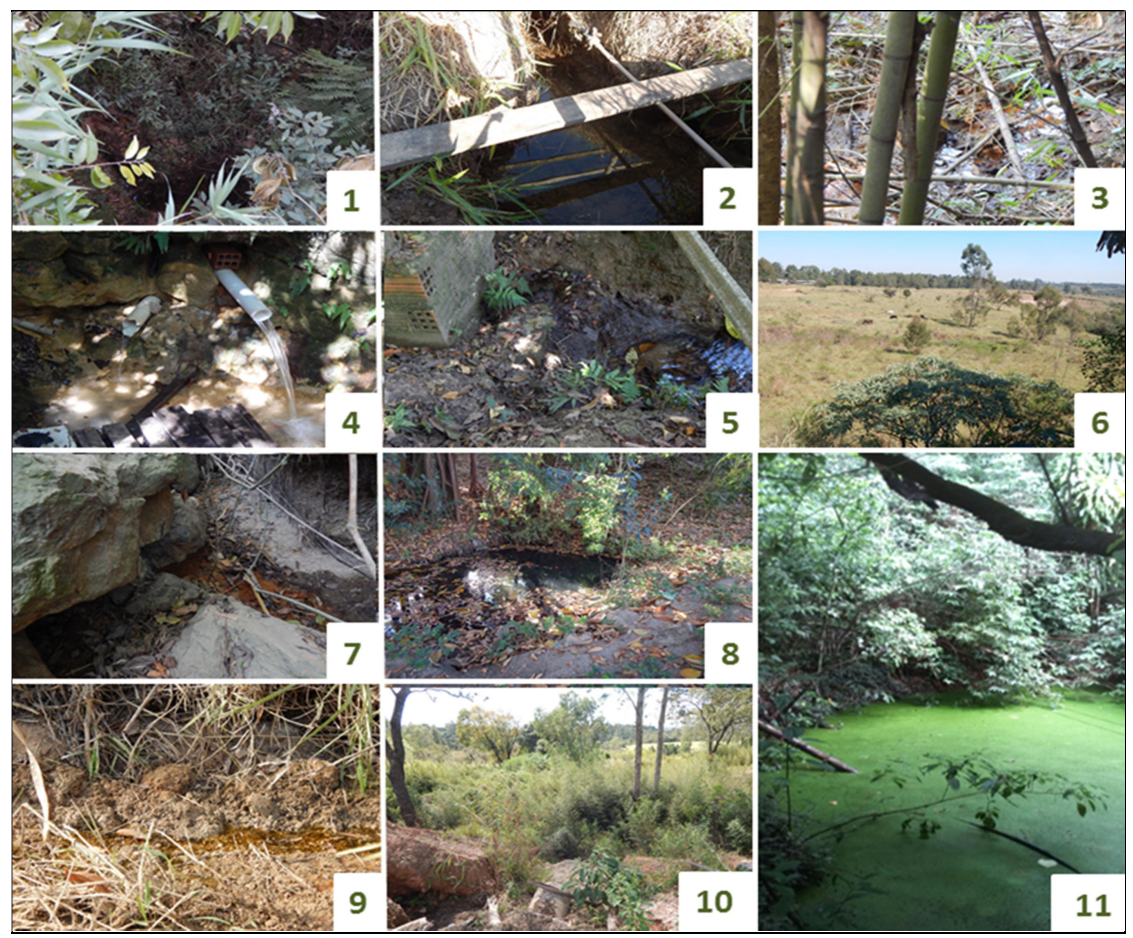

Figura 2. Nascentes visitadas na microbacia do Pirajibu-Mirim (localização mostrada na Figura 1). 1. Nascente próxima à construção de um empreendimento; 2. Afloramento em um pasto de uma propriedade privada; 3. Nascente em um terreno ocioso; 4. Água canalizada em nascente inserida em bairro residencial; 5. Nascente de um imóvel residencial ao lado da represa do Pirajibu; 6. Nascente no terreno de uma empresa; 7. Afloramento ao lado de uma via de circulação; 8. Nascente em uma chácara; 9. Afloramento em uma via de circulação; 10. Nascente em área residencial; 11. Nascente e represamento da água em uma propriedade agrícola. Sorocaba/SP, 2015.

As nascentes que tiveram as vazões encontradas no período do campo podem ser destacadas pela qualidade da água, pois as notas atribuídas nessas categorias foram as maiores. Nenhum despejo de esgoto próximo foi identificado, nem presença de óleos, odores, espumas e materiais flutuantes. Vale destacar que, embora próximos às nascentes esses problemas não existam, em outros trechos de cursos d'água da bacia eles podem ser observados. 
Tabela 2. Resultado do diagnóstico macroscópico aplicado e classificação das nascentes.

\begin{tabular}{|c|c|c|c|c|c|c|c|c|c|c|c|}
\hline & N. 1 & N. 2 & N. 3 & N. 4 & N. 5 & N. 6 & N. 7 & N. 8 & N. 9 & N. 10 & N. 11 \\
\hline Cor da água & 3 & 3 & 3 & 3 & 3 & - & 1 & 2 & 2 & - & 3 \\
\hline Odor & 3 & 3 & 3 & 3 & 3 & - & 3 & 3 & 3 & - & 3 \\
\hline Lixo ao redor & 3 & 3 & 3 & 1 & 3 & 3 & 1 & 3 & 3 & 3 & 2 \\
\hline Materiais flutuantes & 2 & 3 & 3 & 3 & 3 & - & 1 & 3 & 3 & - & 3 \\
\hline Óleos & 3 & 3 & 3 & 3 & 3 & - & 3 & 3 & 3 & - & 3 \\
\hline Espumas & 3 & 3 & 3 & 3 & 3 & - & 3 & 3 & 3 & - & 3 \\
\hline Esgoto & 3 & 3 & 3 & 3 & 3 & - & 3 & 3 & 3 & - & 3 \\
\hline Vegetação (APP) & 2 & 1 & 2 & 2 & 3 & 1 & 2 & 2 & 1 & 2 & 3 \\
\hline Uso por animais & 3 & 1 & 3 & 2 & 1 & 3 & 2 & 2 & 1 & 3 & 3 \\
\hline Uso por humanos & 3 & 1 & 3 & 2 & 1 & 3 & 2 & 2 & 1 & 3 & 1 \\
\hline Proteção do local & 1 & 2 & 1 & 1 & 2 & 1 & 1 & 1 & 1 & 1 & 2 \\
\hline $\begin{array}{l}\text { Proximidade com } \\
\text { instalações urbanas }\end{array}$ & 1 & 1 & 2 & 1 & 1 & 1 & 1 & 2 & 2 & 1 & 2 \\
\hline Área de inserção & 2 & 2 & 2 & 1 & 2 & 2 & 1 & 2 & 1 & 1 & 2 \\
\hline Total & 32 & 29 & 34 & 28 & 31 & - & 24 & 31 & 27 & - & 33 \\
\hline Classificação & C & D & B & D & C & - & $\mathbf{E}$ & C & $\mathbf{E}$ & - & $\mathbf{C}$ \\
\hline
\end{tabular}

Fonte: Tabela 1, adaptado de Gomes et al. (2006).

A nascente 11 é uma caso especial pois, embora não possua esgoto, óleos e espumas, recebe fertilizantes químicos que acentuam a proliferação de algas em seu olho d'água. A contaminação com produtos químicos utilizados na agricultura pode comprometer a qualidade da água, inclusive causando problemas para o consumo humano decorrentes da eutrofização.

As piores avaliações estão relacionadas ao uso e ocupação do solo em áreas adjacentes. A maioria das nascentes apresenta sinais de perturbação antrópica, como degradação ou ausência de vegetação, presença de lixo, inexistência de proteção no local e grande proximidade de residências, indústrias e empreendimentos em construção. Elas também estão inseridas em matriz urbana, não possuindo placas indicativas ou instruções para sua preservação. Além disso, nenhuma está inserida em áreas protegidas, como parques urbanos.

Identifica-se também a necessidade de implantação de técnicas para proteção do solo, especialmente em estradas não pavimentadas, pois diversas nascentes estão próximas ou sobre vias de circulação. A construção de canais para drenagem de escoamento superficial, que levam a água para bacias de contenção, é um exemplo de intervenção que pode auxiliar no controle de erosão nessas áreas (Griebeler et al., 2005). 


\subsection{Adequação ambiental das APPs de curso d'água e nascentes}

Visando a proteção dessas nascentes, foi efetuada uma análise mais detalhada do uso do solo em seus entornos. Essa análise buscou identificar se a paisagem das APPs está compatível com o uso previsto pelo Código Florestal Brasileiro. A lei $n^{\mathrm{o}}$ 12.651/2012 estabeleceu algumas mudanças em relação à recuperação de áreas já consolidadas em APPs. Embora o raio mínimo de preservação ao redor das nascente ainda seja de 50 metros, a recuperação pode se limitar a um raio de 15 metros, se o seu uso foi consolidado antes de 22 de julho de 2008 (Brasil, 2008; 2012).

O órgão ambiental municipal e o órgão ambiental estadual foram consultados para esclarecimento da aplicação da nova lei. Ambos ressaltaram que na decisão prevalece a maior proteção ao meio ambiente, ou seja, se o proprietário quiser recuperar área de apenas 15 metros, ele deverá comprovar que seu uso foi consolidado antes de julho/2008. Assim, em projetos de adequação ambiental, considera-se sempre recuperação de 50 metros de raio em volta das nascentes.

O Código Florestal ainda destaca que áreas de preservação são aquelas "no entorno das nascentes e dos olhos d'água perenes" (Brasil, 2012). Ressalta-se que a aplicação apenas para nascentes perenes foi acrescentada na reformulação do código, diminuindo a necessidade de recuperação de floresta nativa (Faria et al., 2014). Algumas nascentes não estavam com vazão no local apontado pelas cartas do IBGE (1996) quando visitadas em campo. Entretanto, como variações sazonais podem refletir nos seus pontos de afloramento, a simulação da adequação ambiental foi realizada de acordo com as coordenadas geográficas das cartas.

Além da necessidade de proteger o entorno das nascentes, o Código Florestal prescreve a preservação da vegetação nativa das faixas marginais dos cursos d'água, que também compuseram o cálculo. Destaca-se que análises da declividade e altitude também foram consideradas na microbacia. No entanto, não há APPs dessas modalidades na região.

Figueiró e Colau (2014) apontam que o artigo 225 da Constituição Brasileira impõe ao poder público e à coletividade o dever de proteger o meio ambiente. Assim, são responsáveis pela tutela ambiental a União, os estados e os municípios, evidenciando uma tendência de descentralização em sua gestão. Essa descentralização não envolve apenas ações do poder executivo, como fiscalização e execução das leis ambientais, como também implica na possibilidade dos estados e municípios legislarem a respeito do tema.

Há ainda uma particularidade na legislação ambiental, onde os estados e municípios podem modificar parâmetros já dispostos em leis federais. Em caso de conflitos, prevalecerá a lei que for mais restritiva, ou seja, que melhor defenda o meio ambiente.

O município de Sorocaba apresenta um exemplo de parâmetros para conservação mais restritivos do que os indicados na lei federal. O plano diretor estabelece que as APPs devam ser maiores do que no Código Florestal em alguns trechos dos principais rios da cidade. $\mathrm{O}$ rio Pirajibu-Mirim, de acordo com o plano, deve ter faixas de proteção de 60 metros, desde sua cabeceira até sua foz. Um trecho é excluído dessa proteção (entre as coordenadas UTM 258.628,331-7.398.473,266 e 256.149,560-7.400.918,737), além de outras áreas já urbanizadas (Sorocaba, 2014), onde se aplica o Código Florestal.

Essas particularidades foram consideradas no cálculo do uso do solo nas APPs da microbacia (Tabela 3). Portanto, foram considerados raios de 50 metros no entorno das nascentes, faixas de 60 metros no entorno do rio Pirajibu-Mirim, e de 30 metros nos demais cursos d'água e no trecho excluído pelo plano diretor (Brasil, 2012; Sorocaba, 2014).

O estudo sobre o uso do solo mostra que a maior parte das APPs está coberta com vegetação nativa $(57,6 \%)$. Os solos descobertos representam $30,7 \%$, correspondendo às regiões de maior prioridade para a recomposição vegetal. Os plantios florestais ao redor de corpos d'água podem desencadear, em um primeiro momento, uma redução na sua vazão (Ferraz et al., 2013). Embora essenciais para provisão de serviços ecossistêmicos, as árvores 
também são grandes consumidoras da água presente no solo. Ainda assim, elas são indispensáveis para estabilidade do solo, resultando na manutenção e na perpetuação do fluxo de água ao longo do tempo (Lima, 2005). Esses fatores são especialmente importantes quando se trata do manejo de uma microbacia responsável pelo abastecimento público de água.

Tabela 3. Área total e área relativa das categorias do uso do solo em APPs de curso d'água e demais nascentes.

\begin{tabular}{lcc}
\hline \multicolumn{1}{c}{ Uso } & $\begin{array}{c}\text { Área total } \\
\left(\mathrm{km}^{2}\right)\end{array}$ & $\begin{array}{c}\text { Área relativa } \\
(\%)\end{array}$ \\
\hline Fragmentos & 4,90 & 57,6 \\
Pasto/solo descoberto & 2,62 & 30,7 \\
Floresta plantada & 0,42 & 4,9 \\
Instalações urbanas & 0,33 & 3,9 \\
Lagoas & 0,23 & 2,7 \\
\hline Total & $\mathbf{8 , 4 9}$ & $\mathbf{1 0 0}$ \\
\hline
\end{tabular}

Nas áreas onde foram encontradas florestas plantadas (4,9\%) seria necessário o manejo dos indivíduos exóticos e plantio posterior de árvores nativas. A recomposição de APPs com espécies exóticas é uma técnica permitida no novo Código Florestal apenas para pequenos produtores rurais ou posse rural familiar, não sendo aplicada para as áreas onde as plantações de exóticas foram encontradas.

Todavia, os projetos de recuperação devem priorizar áreas de solo descoberto. As florestas plantadas podem trazer algumas características também encontradas em florestas nativas, como controle de erosão e aporte de carbono (Pulrolnick et al., 2009). Se seu manejo for realizado de acordo com modelo de mosaico, onde há plantio de espécies arbóreas nativas intercalado com plantio de exóticas, tal como sugerido por Ferraz et al. (2013), ainda pode estabilizar o uso da água na região.

Por fim, as instalações urbanas $(3,9 \%)$ compõem áreas urbanas consolidadas, o que implica em desconsideração das regras de proteção das APP, desde que não sejam consideradas áreas de risco (Brasil, 2012).

\section{CONCLUSÃO}

O estabelecimento de um projeto de pagamento por serviços ambientais em uma região depende da adoção de uma área prioritária para a conservação de um serviço ambiental. Assim, a microbacia do rio Pirajibu-Mirim foi delimitada para estudo, pois seu rio principal alimenta a represa do Pirajibu e contribui para o abastecimento público de água na cidade.

Uma avaliação de suas nascentes mostrou que, na amostragem considerada, a maioria está inserida em propriedades particulares sem uso econômico do solo. Os principais problemas encontrados envolvem a ausência ou degradação de cobertura vegetal em seus entornos, além de outros sinais de perturbação antrópica. Uma análise de uso e ocupação do solo em todas as APPs da microbacia mostra que 30,7\% apresentam solo descoberto. Essas características demonstram a importância de ações para proteção e recuperação de mananciais do rio Pirajibu-Mirim. Destaca-se que a instituição de uma política pública de incentivo na região deve considerar o perfil das propriedades que possuem nascentes, para assegurar que a preservação dos recursos hídricos seja compatível com os aspectos socioeconômicos 
observados na região.

\section{AGRADECIMENTOS}

À Coordenação de Aperfeiçoamento de Pessoal de Nível Superior - CAPES pela bolsa de mestrado concedida.

\section{REFERÊNCIAS}

AGÊNCIA NACIONAL DE ÁGUAS - ANA (Brasil). O comitê de bacia hidrográfica: prática e procedimento. Cadernos de capacitação em recursos hídricos. Brasília: SAG, 2011. 81 p. Disponível em: http://www.comiteibicui.com.br/cbpp.pdf. Acesso em: 03 dez. 2015.

BRASIL. Decreto $\mathbf{n}^{\mathbf{0}} \mathbf{6 . 5 1 4}$, de 22 de julho de 2008. Dispõe sobre as infrações e sanções administrativas ao meio ambiente, estabelece o processo administrativo federal para apuração destas infrações, e dá outras providências. Disponível em: http://www.planalto.gov.br/ccivil_03/_ato2007-2010/2008/decreto/d6514.htm. Acesso em: 25 jan. 2016.

BRASIL. Lei n. 9433, de 8 de janeiro de 1997. Institui a Política Nacional de Recursos Hídricos, cria o Sistema Nacional de Gerenciamento de Recursos Hídricos, regulamenta o inciso XIX do art. 21 da Constituição Federal, e altera o art. $1^{\circ}$ da Lei $n^{\circ} 8.001$, de 13 de março de 1990, que modificou a Lei ${ }^{\circ}$ 7.990, de 28 de dezembro de 1989. Disponível em: http://www.planalto.gov.br/ccivil_03/leis/19433.htm. Acesso: 30 nov. 2015.

BRASIL. Lei n. 12651, de 25 de maio de 2012. Dispõe sobre a proteção da vegetação nativa; altera as Leis nos 6.938, de 31 de agosto de 1981, 9.393, de 19 de dezembro de 1996, e 11.428, de 22 de dezembro de 2006; revoga as Leis nos 4.771, de 15 de setembro de 1965, e 7.754, de 14 de abril de 1989, e a Medida Provisória no 2.166-67, de 24 de agosto de 2001; e dá outras providências.. Disponível em: http://www.planalto.gov.br/ccivil_03/_Ato2011-2014/2012/Lei/L12651.htm. Acesso em: 30 nov. 2015.

BOHLEN, P. J. Paying for environmental services from agricultural lands: an example from the northern Everglades. Frontiers in Ecology and the Environment, v. 7, p. 46-55, 2009. http://dx.doi.org/10.1890/080107

CENTRO DE PESQUISAS METEOROLÓGICAS E CLIMÁTICAS APLICADAS A AGRICULTURA - CEPAGRI. Clima dos municípios paulistas. 2015. Disponível em: http://www.cpa.unicamp.br/outrasinformacoes/clima_muni_228.html. Acesso em: 20 jan. 2016.

EZZINE-DE-BLAS, D.; WUNDER, S.; RUIZ-PÉREZ, M.; MORENO-SANCHEZ, R. P. Global Patterns in the Implementation of Payments for Environmental Services. PLoS ONE, v. 11, n. 3, 2016. http://dx.doi.org/10.1371/journal.pone.0149847

FARIA, L. C. de; ADRIANO JUNIOR, F. C.; TONELlO, K.C. ; VALENTE, R. O. A. Reflexos das alterações no Código Florestal Brasileiro em Áreas de Preservação Permanentes de duas propriedades rurais em Itu e Sarapuí, SP. Revista Ambiente \& Água, v. 9, p. 559-568, 2014. http://dx.doi.org/10.4136/ambi-agua.1354 
FERRAZ, S. F. B.; LIMA, W. P.; RODRIGUES, C. B. Managing forest plantation landscapes for water conservation. Forest Ecology and Management, v. 301, p. 58-66, 2013. http://dx.doi.org/10.1016/j.foreco.2012.10.015

FIGUEIRÓ, F. S.; COLAU, S. G. Competência legislativa ambiental e aplicação da norma mais restritiva como forma de resolução de conflitos: uma análise crítica. Veredas do Direito, v. 11, n. 21, p. 255-280, 2014.

GOMES, P. M.; MELO, C.; VALE, V. S. Avaliação dos impactos ambientais em nascentes na cidade de Uberlândia-MG: Análise macroscópica. Sociedade e Natureza, v. 17, n. 32, p. 103-120, 2006.

GRIEBELER, N. P.; PRUSKI, F. F.; SILVA, J. M. A.; RAMOS, M. M.; SILVA, D. D. Modelo para a determinação do espaçamento entre desaguadouros em estradas não pavimentadas. Revista Brasileira de Ciência do Solo, v. 29, n. 3, p. 397-406, 2005.

GUEDES, F. B.; SEEHUSEN, S. E. Pagamentos por serviços ambientais na Mata Atlântica: lições aprendidas e desafios. Brasília: MMA, 2011. 272p.

INSTITUTO BRASILEIRO DE GEOGRAFIA E ESTATÍSTICA - IBGE. Cidades. 2015. Disponível em: http://cidades.ibge.gov.br/xtras/perfil.php?codmun=355220. Acesso em: 23 jan. 2016.

INSTITUTO BRASILEIRO DE GEOGRAFIA E ESTATÍSTICA - IBGE. Loja do IBGE. 1996. Disponível em: http://loja.ibge.gov.br/cartas-mapas-e-cartogramas/mapeamentotopografico. Acesso em: 15 set. 2016.

INSTITUTO GEOGRÁFICO E CARTOGRÁFICO - IGC. Mapa das unidades hidrográficas de gerenciamento de recursos hídricos. 2014. Disponível em: http://www.igc.sp.gov.br/produtos/ugrhi.html. Acesso em: 23 jan. 2016.

LIMA, W. P. A floresta natural protege e estabiliza recursos hídricos. Visão Agrícola, v. 4, p. 30-33, 2005.

LOURENÇO, R. W.; SIlvA, D. C. C.; SAlES, J. C. A.; CRESPO, G. C.; PIÑARODRIGUES, F. C. M. Geoprocessamento como ferramenta de gestão e planejamento ambiental: $\mathrm{O}$ caso da cobertura vegetal em áreas urbanas. In: SMITH, W. S.; MOTA JR., V. D. da; CARVALHO, J. de L. (Orgs.). Biodiversidade no município de Sorocaba. Sorocaba: Secretaria do meio ambiente, 2014. p. 65-77.

PORTO, M. F. A.; PORTO, R. L. L. Gestão de bacias hidrográficas. Estudos Avançados, v. 22, n. 63, p. 43-60, 2008. http://dx.doi.org/10.1590/S0103-40142008000200004

PULROLNIK, K; BARROS, F. N.; SILVA, I. R.; NOVAIS, R. F.; BRANDANI, C. B. Estoques de carbono e nitrogênio em frações lábeis e estáveis da matéria orgânica de solos sob eucalipto, pastagem e cerrado no vale do Jequitinhonha - MG. Revista $\begin{array}{lllllll}\text { Brasileira de Ciência do Solo, v. 33, p. 1125-1136, } 2009 . & \end{array}$ http://dx.doi.org/10.1590/S0100-06832009000500006

ROSA, F. S.; TONELLO, K. C.; LOURENÇO, R. W. Eleição de áreas prioritárias para pagamento por serviços ambientais: uma análise em nível de microbacia. Revista Ambiente \& Água, v. 11, n. 02, p. 448-461,2016. http://dx.doi.org/10.4136/ambiagua. 1809 
SCHOMERS; S.; MATZDORF, B. Payments for ecosystem services: A review and comparison of developing and industrialized countries. Ecosystem Services, v. 6, p. 1630, 2013. http://dx.doi.org/10.1016/j.ecoser.2013.01.002

SERVIÇO AUTONÔMO DE ÁGUA E ESGOTO - SAAE. Água. 2014. Disponível em: http://www.saaesorocaba.com.br/. Acesso em: 04 fev. 2016.

SOROCABA. Lei $\mathbf{n}^{0}$ 11.022, de 16 de dezembro de 2014. Dispõe sobre a revisão do Plano Diretor de Desenvolvimento Físico Territorial do Município de Sorocaba e dá outras providências. Sorocaba, 16 dez. 2014. Disponível em: http://www.sorocaba.sp.gov.br/portal/servicos/plano-diretor-lei-n-11-022-de-16-dedezembro-de-2014. Acesso em: 28 jan. 2016.

SOROCABA. Lei $\mathbf{n}^{\mathbf{0}} \mathbf{9 . 8 1 2}$, de 16 de novembro de 2011. Dispõe sobre pagamentos por serviços ambientais para proprietários de imóveis situados na Bacia do Rio Pirajibu e dá outras providências. Sorocaba, 16 nov. 2011. Disponível em: http://leismunicipa.is/fdnto. Acesso em 28 jan. 2016.

WUNDER, S. Pagamentos por serviços ambientais: perspectivas para a Amazônia Legal. Brasília: MMA, 2008. 146 p. 